\title{
Bonding effectiveness of experimental one-step self-etch adhesives to sound and caries-affected dentin
}

\author{
Cristina P. Isolan ${ }^{\mathrm{a}}$, Ana Carolina U. Vasconcelos ${ }^{\mathrm{a}}$, Maximiliano S. Cenci ${ }^{\mathrm{a}}$, Maria Elisa M. Moura ${ }^{\mathrm{b}}$, \\ Victor P. Feitosa ${ }^{\mathrm{b}}$, Rafael R. Moraes ${ }^{\mathrm{a}, *}$ \\ a Graduate Program in Dentistry, Federal University of Pelotas, Rua Gonçalves Chaves 457, 96015-560 Pelotas, RS, Brazil \\ ${ }^{\mathrm{b}}$ Graduate Program in Dentistry, Federal University of Ceará, Brazil
}

\section{A R T I C L E I N F O}

\section{Keywords:}

Caries-affected dentine

Hybrid layer

Self-etch adhesive

\begin{abstract}
A B S T R A C T
Experimental one-step, self-etch adhesives containing different contents of an acidic methacrylate monomer (GDMA-P) were formulated and their effectiveness in bonding to sound dentin (SoD) or caries-affected dentin (CAD) was investigated. The CAD was obtained using a microcosm biofilm model. HEMA-based adhesives were formulated with 5, 20, or $35 \mathrm{wt} \%$ of GDMA-P (AD5, AD20, AD35), with pH ranging between $1.05 \pm 0.05$ and $1.93 \pm 0.15$. Shear bond strength to dentin was assessed after storage for $24 \mathrm{~h}$ or 6 months. Morphology of the bonded interfaces was observed using SEM. The exposed collagen area at bonded interfaces was measured using a histological staining technique. Degree of $\mathrm{C}=\mathrm{C}$ conversion within the hybrid layer, measured by micro-Raman spectroscopy, indicated that $\mathrm{AD} 35$ had lower in situ $\mathrm{C}=\mathrm{C}$ conversion than the other adhesives. A more evident exposed collagen zone along the base of the hybrid layer was observed in CAD samples. The hybrid layer was generally thicker in CAD. AD20 had the highest in situ $\mathrm{C}=\mathrm{C}$ conversion and yielded stable bond strengths that were generally independent of the dentin condition. Additionally, the bonding effectiveness was dependent on adhesive acidity, type of dentin bonding substrate, and water storage time.
\end{abstract}

\section{Introduction}

Dental caries is one of the most common oral diseases in humans [25]. Caries lesions extending to dentin are usually associated with the placement of restorations. Under the concepts of minimally invasive dentistry, decayed dental tissue located at the inner layer of the cavity may be only partially removed [13], thus the restorative procedure would include bonding to both sound dentin (SoD) and caries-affected dentin (CAD). CAD may still remain in the cavity even when a complete removal of the caries lesion is performed. Several studies indicate that bonding to $\mathrm{CAD}$ is more challenging than bonding to sound dentin $[2,9,37,40]$ since the morphological and chemical alterations in CAD $[3,22]$ may result in unfavorable conditions for effective adhesion $[14,19]$.

Bonding to enamel and dentin can follow two different strategies, i.e. etch-and-rinse or self-etch approaches. Depending on the strategy, the resulting bonded substrate might present different characteristics. The etch-and-rinse strategy removes the dentin smear layer completely, leaving the tubules open for resin infiltration, and generates an up to $10 \mu \mathrm{m}$ thick layer of demineralized collagen prone to hybridization. By contrast, the self-etch strategy only modifies the smear layer, resulting in a few micrometers thick layer of partially demineralized collagen infiltrated by resin. In teeth presenting CAD, self-etch adhesives would be incorporated to the bonding substrate. Previous studies reported that etch-and-rinse adhesives performed better than self-etch adhesives applied to $\mathrm{CAD}[2,40]$. However, self-etch materials are increasingly popular in dentistry, especially due to their easier application and less sensitive bonding protocol.

One-step, self-etch adhesives have the simplest application protocol amongst all dental adhesives, but also the most complex composition. In one-step systems, however, all components are mixed together, including resin monomers (acidic, hydrophilic, hydrophobic), solvents, water, and photoinitiators. These adhesives are usually very hydrophilic and subject to hydrolysis over time, thus their long-term bonding performance is often contested [4]. Previous studies [11,18] show that the concentration of acidic monomers incorporated into two-step, selfetch adhesives might influence the immediate and long-term dentin bond strengths [11,18]. However, there are still few studies investigating the impact of formulation components on the bonding performance of one-step adhesives to CAD [24]. The aim of this study was to investigate bonding effectiveness of one-step, self-etch adhesives containing different contents of acidic monomer applied to SoD and

\footnotetext{
* Corresponding author.

E-mail address: moraesrr@gmail.com (R.R. Moraes).
} 
Table 1

Components of the experimental one-step, self-etch adhesives tested (wt\%).

\begin{tabular}{|c|c|c|c|c|c|c|c|c|c|}
\hline \multirow[t]{2}{*}{ Reagent } & \multicolumn{3}{|l|}{ AD5 } & \multicolumn{3}{|l|}{ AD20 } & \multicolumn{3}{|l|}{ AD35 } \\
\hline & Bottle A & Bottle B & $A+B$ & Bottle A & Bottle B & $A+B$ & Bottle A & Bottle B & $A+B$ \\
\hline GDMA-P & $10 \%$ & - & $5 \%$ & $40 \%$ & - & $20 \%$ & $70 \%$ & - & $35 \%$ \\
\hline HEMA & $65 \%$ & $15 \%$ & $40 \%$ & $35 \%$ & $15 \%$ & $25 \%$ & $5 \%$ & $15 \%$ & $10 \%$ \\
\hline Bis-GMA & $10 \%$ & $50 \%$ & $30 \%$ & $10 \%$ & $50 \%$ & $30 \%$ & $10 \%$ & $50 \%$ & $30 \%$ \\
\hline Water & - & $20 \%$ & $10 \%$ & - & $20 \%$ & $10 \%$ & - & $20 \%$ & $10 \%$ \\
\hline Ethanol & $15 \%$ & $15 \%$ & $15 \%$ & $15 \%$ & $15 \%$ & $15 \%$ & $15 \%$ & $15 \%$ & $15 \%$ \\
\hline $\mathrm{pH}($ mean $\pm \mathrm{SD})$ & \multicolumn{3}{|c|}{$1.93 \pm 0.15^{\mathrm{A}}$} & \multicolumn{3}{|c|}{$1.25 \pm 0.04^{\mathrm{B}}$} & \multicolumn{3}{|c|}{$1.05 \pm 0.05^{\mathrm{C}}$} \\
\hline
\end{tabular}

Distinct letters indicate statistically significant differences in $\mathrm{pH}$ between the adhesives $(\mathrm{p}<0.05)$.

Labels AD5, AD20, and AD35 refer to the concentrations of GDMA $=\mathrm{P}$ after mixing bottles $\mathrm{A}+\mathrm{B}$.

CAD. The study hypothesis was that CAD would be a more challenging bonding substrate than SoD irrespective of the acidic methacrylate concentration in the adhesive.

\section{Materials and methods}

\subsection{Preparation of dentin discs}

Bovine incisors were cleaned and stored in $0.5 \%$ chloramine-T solution for seven days. Standardized enamel-dentin discs with $2 \mathrm{~mm}$ in thickness and $6 \mathrm{~mm}$ in diameter were cut from the buccal surfaces of the teeth using a water-cooled trephine drill. The discs were wet-ground using 80-grit $\mathrm{SiC}$ abrasive papers until superficial dentin was visually exposed, then wet-polished with 600-grit $\mathrm{SiC}$ abrasive papers for $1 \mathrm{~min}$ to standardize the smear layer. All discs $(n=174)$ were inspected with $40 \times$ magnification stereomicroscope to ensure the absence of enamel. The dentin discs were randomly assigned to two group: SoD or CAD. The SoD discs were not subjected to any further treatment, whereas the CAD discs had all surfaces except the buccal coated with nail varnish. The buccal surface was left uncoated to undergo the cariogenic challenge detailed in subheading 2.2. All discs were sterilized using gamma radiation and kept at $4^{\circ} \mathrm{C}$ in a humid atmosphere until use.

\subsection{Formation of artificially-induced $C A D$}

The experimental setup used to induce the formation of CAD was described elsewhere [15] and it was approved by the local Research Ethics Committee (protocol 25/2013). Fresh saliva (20 mL) stimulated by paraffin film was collected from a healthy volunteer (a 48-year-old female) who had not been under antibiotic therapy for the past six months. The volunteer abstained from oral hygiene for $24 \mathrm{~h}$ and from food ingestion for $2 \mathrm{~h}$ before collection. No saliva volume was discarded before collection. A volume of $0.4 \mathrm{~mL}$ of this saliva was inoculated onto each dentin disc $(n=87)$ in a 24-microwell plate and remained for $1 \mathrm{~h}$ at $37^{\circ} \mathrm{C}$. The saliva was then gently aspirated from the bottom of each well and $1.8 \mathrm{~mL}$ of defined medium enriched with mucin (DMM) $[35,36]$ containing $1 \%$ sucrose was added. The plates were incubated at $37^{\circ} \mathrm{C}$ under an anaerobic atmosphere $\left(5-10 \% \mathrm{CO}_{2}\right.$, less than $1 \% \mathrm{O}_{2}$ ) [30]. After $4 \mathrm{~h}$, the specimens were rinsed with $2 \mathrm{~mL}$ of sterile saline, placed into a new plate containing DMM without sucrose, and incubated for another $20 \mathrm{~h}$ under the same conditions. The biofilms were formed individually on the specimens in each well for 14 days, during which the same daily routine of alternate exposure to DMM supplemented or not with sucrose was followed. Previous experiments showed similar results when saliva from different donors were used in the same conditions [23]. A cross-sectional hardness test was performed to measure the integrated hardness loss $(\Delta S)$ and confirm the formation of artificially-induced CAD [15]. Briefly, four CAD specimens were longitudinally sectioned using a water-cooled diamond saw, embedded in PVC tubes using poly(methyl)methacrylate, and wet polished with 600-, 1200-, 1500-, and 2000-grit SiC abrasive papers, and with a $1 \mu \mathrm{m}$ diamond suspension. Cross-sectional Knoop hardness measurements were performed using a microindenter (FM-700; FutureTech, Tokyo, Japan) under a load of $5 \mathrm{~g}$ and a dwell time of $5 \mathrm{~s}$. Two columns each with eight indentations were performed in the specimens at distances of $10,20,30,40,50,100,150$, and $200 \mu \mathrm{m}$ from the surface. The $\Delta \mathrm{S}$ was calculated by subtracting the hardness profile (Knoop hardness number, $\mathrm{kgf} / \mathrm{mm}^{2}$ ) of the CAD from the hardness values obtained in the sound substrate.

\subsection{Formulation of experimental one-step, self-etch adhesives}

Three 2-component, one-step self-etch adhesives were prepared by mixing the following componentes: bisphenol-A glycidyl dimethacrylate (Bis-GMA, MW $=512.6 \mathrm{~g} / \mathrm{mol}$ ) as hydrophobic monomer; 2-hydroxyethyl methacrylate (HEMA, MW $=130.1 \mathrm{~g} / \mathrm{mol}$ ) as hydrophilic monomer; 1,3-glycerol dimethacrylate phosphate (GDMA-P, MW = $413.3 \mathrm{~g} / \mathrm{mol}$ ) as acidic monomer; water and ethanol as solvents; and camphorquinone $(0.4 \mathrm{wt} \%)$ and 4-ethyl-dimethylamino benzoate $(0.8 \mathrm{wt} \%)$ as photoinitiators. All monomers were obtained from Esstech Inc. (Essington, PA, USA) except for GDMA-P, which was synthesized as previously described [11]. The concentration of HEMA and GDMA-P varied in the adhesives, as shown in Table 1 . The adhesives were prepared using two distinct bottles (A and B), as detailed in Table 1. Before application of the adhesive, $5 \mu \mathrm{L}$ from each bottle were dispensed into a mixing dish using a micropipette and mixed for $5 \mathrm{~s}$. The final concentrations of acidic monomer after mixing the two bottles were $5 \mathrm{wt} \%$, $20 \mathrm{wt} \%$, and $35 \mathrm{wt} \%$, thus the adhesives were labeled AD5, AD20, and AD35. The $\mathrm{pH}$ of the mixed adhesives $(\mathrm{n}=3)$ was measured using a digital pHmeter (An2000; Analion, Ribeirão Preto, SP, Brazil).

\subsection{Shear bond strength test and failure mode analysis}

The dentin discs (60 SoD, $60 \mathrm{CAD}$ ) were cleaned with a toothbrush and distilled water and embedded in PVC tubes using poly(methyl) methacrylate [21]. The adhesives were vigorously applied to the dentin surfaces for $20 \mathrm{~s}$ using a microbrush, followed by air-drying for $10 \mathrm{~s}$ with a mild air stream. Elastomer molds with two cylindrical orifices (diameter $1.5 \mathrm{~mm}$, thickness $0.5 \mathrm{~mm}$ ) were placed at the center of the top dentin surfaces. The adhesive was photoactivated for $20 \mathrm{~s}$ using a light-emitting diode curing unit (Radii; SDI, Bayswater, Victoria, Australia) with $800 \mathrm{~mW} / \mathrm{cm}^{2}$ irradiance. The orifices were filled with composite resin (Filtek Z350 XT; 3 M ESPE, St. Paul, MN, USA), which were photoactivated for $20 \mathrm{~s}$, to produce cylinder specimens with 1.77 $\mathrm{mm}^{2}$ bonded area. The specimens were stored in distilled water at $37^{\circ} \mathrm{C}$ for $24 \mathrm{~h}$ or 6 months, with renewal of the storage medium every month. For the shear bond strength test, a stainless steel wire $0.2 \mathrm{~mm}$ diameter) was looped around each cylinder and aligned with the bonded interface. The test was performed using a mechanical testing machine (DL500; EMIC, São José dos Pinhais, PR, Brazil) at a crosshead speed of $0.5 \mathrm{~mm} / \mathrm{min}$ until failure. In total, 20 cylinder specimens were tested for each adhesive, substrate, and storage time combination. Fractured 

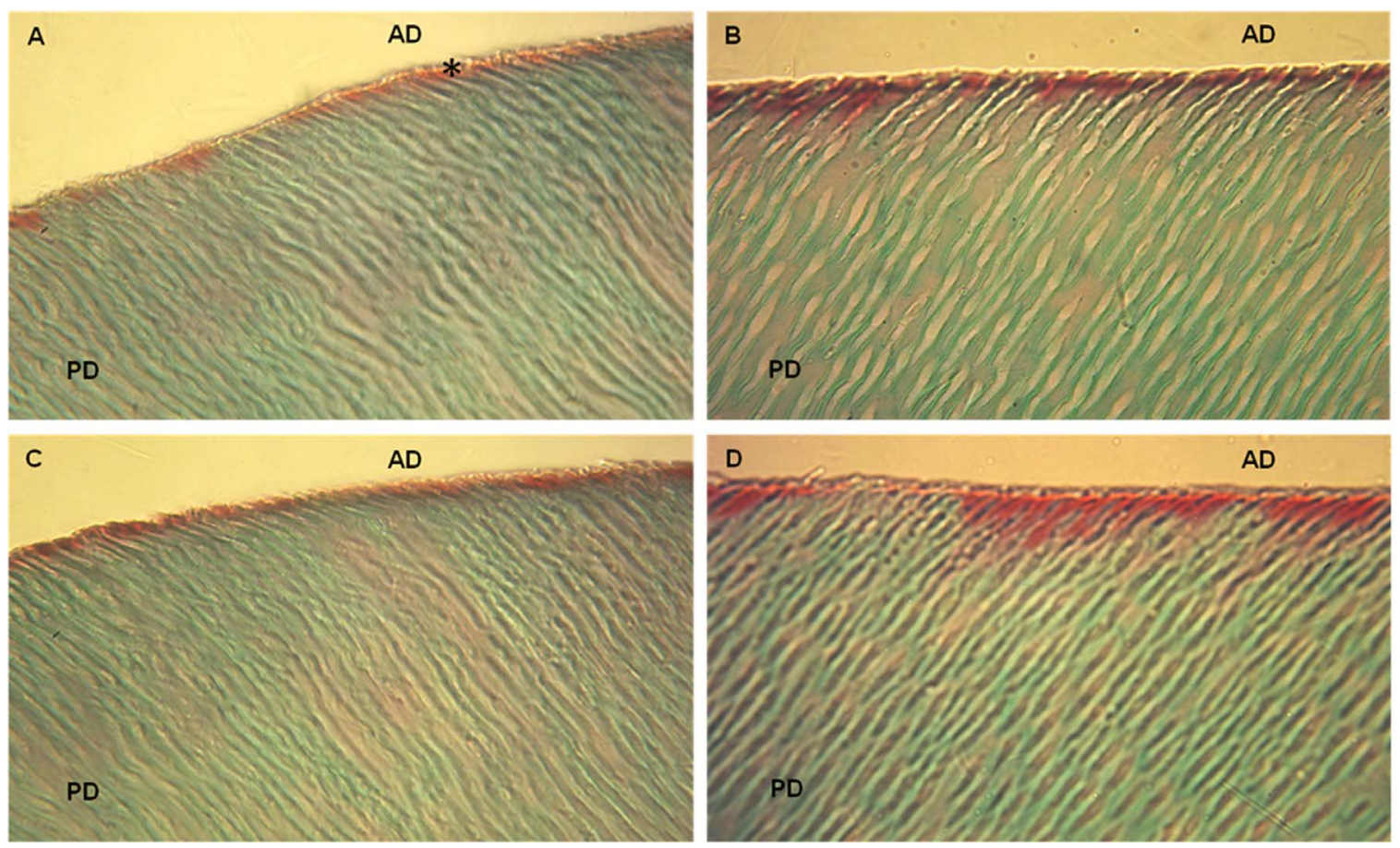

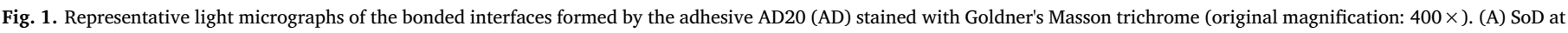

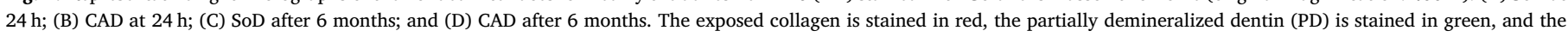

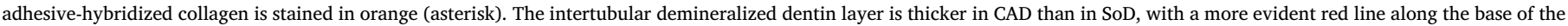
hybrid layer. (For interpretation of the references to color in this figure legend, the reader is referred to the web version of this article.)

specimens were observed under $40 \times$ magnification using a stereomicroscope to observe the failure mode: adhesive (interfacial failure) or mixed failure (partially adhesive and partially cohesive within the dentin).

\subsection{In situ degree of $C=C$ conversion within the hybrid layer}

The three experimental adhesives were applied to other dentin discs $(n=6)$ as previously described. The specimens were then sectioned longitudinally across the bonded interfaces to obtain two resin-dentin slices that were wet-polished with 1200- and 2500-grit SiC papers for $60 \mathrm{~s}$ each. The specimens were ultrasonically cleaned for $2 \mathrm{~min}$ in distilled water and air-dried. The in situ degree of $\mathrm{C}=\mathrm{C}$ conversion (DC) was measured within the hybrid layer using a micro-Raman spectrometer (Xplora; Horiba, Paris, France). The spectrometer was calibrated at zero and for coefficient values using a standard silicon specimen. The parameters used were: $20 \mathrm{~mW}$ neon laser with $532 \mathrm{~nm}$ wavelength, spatial resolution of $3 \mathrm{~mm}, 5 \mathrm{~cm}^{-1}$ spectral, accumulation time of $10 \mathrm{~s}$ with 4 accumulations, and $100 \times$ magnification (Olympus, London, UK) to obtain a $1 \mu \mathrm{m}$ diameter beam. Polymer spectra were taken at three different sites for each adhesive interface and the values were averaged. Spectra of the uncured adhesives were used as references. Post-processing of the spectra was performed using LabSpec software v.6.1 (Horiba) using baseline correction and normalization of the range between 1590 and $1660 \mathrm{~cm}^{-1}$. \%DC was calculated as previously described [16].

\subsection{SEM morphological analysis of the bonded interfaces}

Two additional dentin discs for each substrate and for each group (n $=24$ ) were tested. Each adhesive system was applied as described before and the two discs in each group were bonded to each other using composite resin (Filtek Z350 XT, 3M ESPE), generating a dentin-composite-dentin sandwiched specimen. The specimens were embedded cross-sectionally in epoxy resin for visualization of the dentin-composite interfaces. After $24 \mathrm{~h}$, the surfaces were wet-polished with 600-, 1200-, 1500-, and 2000-grit SiC abrasive papers and with 3-, $1-$, and $0.5-\mu \mathrm{m}$ diamond suspensions. The surfaces were etched with a $50 \%$ phosphoric acid aqueous solution for $5 \mathrm{~s}$ and deproteinized by immersion in $2.5 \% \mathrm{NaOCl}$ aqueous solution for $10 \mathrm{~min}$. The specimens were ultrasonically cleaned with distilled water and dried in a container with silica gel for $2 \mathrm{~h}$ at room temperature. The polished surfaces were coated with gold and the bonded interfaces examined using scanning electron microscopy - SEM (JSM 6610, JEOL, Tokyo, Japan).

\subsection{Histological analysis}

Additional dentin specimens for each group tested $(n=24)$ were treated with the adhesives and two dentin discs were bonded to each other using photoactivated composite resin (Filtek Z350 XT, 3 M ESPE), generating dentin-composite-dentin sandwiched specimens. These specimens were cut in a precision cutting machine to obtain three slices ( $2 \mathrm{~mm}$ thick $\times 2 \mathrm{~mm}$ wide $\times 5 \mathrm{~mm}$ long) per specimen. The slices were fixed in $10 \%$ formalin solution for $48 \mathrm{~h}$ and slightly demineralized in $10 \%$ Morse solution for $48 \mathrm{~h}$ without agitation. The slices were washed in running tap water for $24 \mathrm{~h}$, neutralized in a $5 \%$ sodium sulfate solution for the same period, washed with water again for $24 \mathrm{~h}$, dehydrated in a series of increasing concentrations of ethanol solutions $(70 \%$ to $100 \%$ ), cleared in xylol, and embedded in paraffin under vacuum. Serial sections ( $4 \mu \mathrm{m}$ thickness) were cut from the slices with a microtome (820 Spencer Microtome; American Optical, Buffalo, NY, USA) and stained with Goldner's Masson trichrome [26]. In this staining technique, green indicates the mineralized dentin, beige the adhesive layer, orange the collagen-resin hybridized layer, and dark red indicates the exposed collagen. The histological sections were digitized using a light microscope (Nikon Eclipse E200; Nikon, Tokyo, Japan) connected to a video camera (Moticam 5.0; Motic ${ }^{\circledR}$, Xiamen, China) and a computer operating with Image Pro Capture Kit Platform (Media Cybernetics; Bethesda, MD, USA). The images were captured using a $10 \times$ objective lens. For each slide, as many fields of $540 \mu \mathrm{m}$ as necessary 
were captured to include the entire region of interest (Fig. 1). Sixty four images were then obtained for each specimen. A calibrated blinded examiner analyzed the images. The calibration consisted of evaluating twice a series of 20 histological images in two different moments. The results of these two evaluations were subjected to a paired $t$-test and Pearson's correlation coefficient, showing no significant differences $(p>0.05)$ and a strong correlation $(r>0.9)$. The exposed collagen was quantified by means of a semi-automated segmentation technique [34].

\subsection{Statistical analysis}

All data were statistically analyzed with SigmaStat v.3.5 software (Systat Software Inc., San Jose, CA, USA). pH data were analyzed using One-way Analysis of Variance (ANOVA). DC and bond strength data were analyzed using Two-way ANOVA (adhesive vs. substrate). Bond strength data between $24 \mathrm{~h}$ and 6 months for each adhesive and substrate were compared using $t$-tests. Data were transformed to ranks before the analysis when necessary. Total counts of exposed collagen mesh were analyzed using ANOVA on Ranks. All pairwise multiple comparison procedures were carried out using the Student-NewmanKeuls' method. A significance level of $\alpha=0.05$ was considered in all analyses.

\section{Results}

The $\Delta S$ values ranged from 2,030 to 2,964 in CAD specimens, with a lesion depth between 100 and $150 \mu \mathrm{m}$, confirming the formation of artificially-induced CAD. Representative light micrographs of bonded interfaces formed by AD20 stained with Goldner's Masson trichrome are shown in Fig. 1. The intertubular demineralized dentin layer was thicker in CAD than in SoD, with a more evident exposed collagen zone along the base of the hybrid layer. The acidic monomer content was associated with lower $\mathrm{pH}$ of the adhesives (Table 1). The results for in situ DC are shown in Table 2. Whereas the factor 'adhesive' was significant ( $p<0.001)$, the factor 'substrate' $(p=0.291)$ or the interaction between the two factors ( $p=0.651$ ) were not significant. The adhesive AD35 had significantly lower DC than the other adhesives in general.

Results for shear bond strength at $24 \mathrm{~h}$ and 6 months are also shown in Table 2. At $24 \mathrm{~h}$, the factor 'adhesive' was not significant ( $\mathrm{p}=$ 0.138 ), whereas the factor 'substrate' and the interaction between factors were significant $(\mathrm{p}<0.001$ ). Bonding to SoD $v s$. CAD at $24 \mathrm{~h}$ was always significantly different. The bond strength to SoD was higher than to CAD for the adhesives AD5 and AD35, but lower for AD20. In SoD groups, AD35 had better immediate bonding performance than $\mathrm{AD} 20$, whereas in CAD groups the adhesive AD20 had the best results. After 6 months, both factors and their interaction were significant ( $\mathrm{p} \leq$ 0.01 ). AD20 was the only adhesive showing significant differences in bond strength between the substrates, with better results in CAD samples. The bond strength of AD35 was higher than the other adhesives after 6 months, irrespective of the bonding substrate. Comparisons for each adhesive between $24 \mathrm{~h}$ and 6 months are presented in Table 2 . AD20 was the only material showing stable dentin bond strengths overtime, irrespective of the dentin substrate tested. AD5 applied to SoD showed lower bond strength after 6 months. Interestingly, AD35 applied to CAD had poorer performance at $24 \mathrm{~h}$. Failure modes (Fig. 2) indicated a predominance of adhesive failures for all adhesives, dentin substrates, and storage periods tested. The occurrence of mixed failures seemed to be less frequent when the adhesives were tested after 6 months of storage.

In the SEM analysis of the bonded interfaces (Fig. 3), it could be observed that all adhesives were able to impregnate both substrates in a similar mode. The SoD surface was always flat, whereas the CAD surface was irregular, in some cases, likely a result of the formation of caries lesions. The hybrid layer was generally thicker in CAD than in SoD samples. Results for the amount of exposed collagen in SoD and CAD bonded substrates are shown in Table 3. No appreciable differences between the substrates were generally observed. The only significant difference between SoD and CAD samples was observed for AD20 at $24 \mathrm{~h}$, with greater exposed collagen area in CAD. At $24 \mathrm{~h}$, AD35 had greater exposed collagen area in SoD than AD20, which had lower exposed collagen in SoD than the other adhesives at 6 months. The highest average fold increase in exposed collagen area between $24 \mathrm{~h}$ and 6 months samples was observed for AD20 applied to SoD, whereas AD35, for instance, showed no major changes with time.

\section{Discussion}

Results of the present study provide evidence that both the composition of self-etch adhesives and conditions of the bonding substrate are important for the overall performance of dental bonded interfaces. Adhesives with higher acidic monomer content had lower $\mathrm{pH}$, which is a significant factor in dental adhesion $[5,12,18]$. Self-etch adhesives are acidic in nature due to their need in demineralizing the dental substrate for infiltration. Although the $\mathrm{pH}$ of the adhesives AD20 and AD35 were numerically close to each other, i.e., 1.2 and 1.0 respectively, the latter was two times more acidic than the former, since $\mathrm{pH}$ is the negative decadic logarithm of the hydrogen ion concentration. This means that even small reductions in $\mathrm{pH}$ may correspond to significant gains in acidity [10]. In the same context, AD35 was approximately nine times more acidic than AD5.

Despite the gain in acidity that materials present upon incorporation of higher amounts of acidic monomer, it has been reported that greater acidity may be associated with poorer polymerization potential [17]. In fact, the adhesive with the highest content of GDMA-P (AD35) showed the poorest in situ DC, which is explained by the negative effects of unreacted acidic species over the reactivity of aliphatic $\mathrm{C}=\mathrm{C}$. In contrast, no significant differences in DC were observed between AD5 and AD20. This finding is probably a result of the higher viscosity of AD20, due to the higher concentration of GDMA-P, increasing the system reactivity and reducing the negative effects of the lower $\mathrm{pH}$ [41]. When HEMA was replaced by GDMA-P, which has higher molecular weight,

Table 2

Means \pm SD for in situ degree of $\mathrm{C}=\mathrm{C}$ conversion (DC) and dentin bond strengths at $24 \mathrm{~h}$ and 6 months.

\begin{tabular}{|c|c|c|c|c|c|c|}
\hline & \multicolumn{2}{|l|}{ In situ DC, \% } & \multicolumn{4}{|c|}{ Bond strength, $\mathrm{MPa}$} \\
\hline & \multirow[b]{2}{*}{ SoD } & \multirow[b]{2}{*}{ CAD } & \multicolumn{2}{|l|}{$24 \mathrm{~h}$} & \multicolumn{2}{|l|}{6 months } \\
\hline & & & SoD & $\mathrm{CAD}$ & SoD & CAD \\
\hline AD5 & $66.6 \pm 8.1^{\mathrm{A}, \mathrm{ab}}$ & $66.7 \pm 2.4^{\mathrm{A}, \mathrm{a}}$ & $5.8 \pm 2.5^{\mathrm{A}, \mathrm{ab}}$ & $3.8 \pm 1.5^{\mathrm{B}, \mathrm{b}}$ & $3.9 \pm 0.5^{\mathrm{A}, \mathrm{b}}$ & $4.3 \pm 1.0^{\mathrm{A}, \mathrm{c}}$ \\
\hline AD20 & $72.3 \pm 4.8^{\mathrm{A}, \mathrm{a}}$ & $69.8 \pm 4.4^{\mathrm{A}, \mathrm{a}}$ & $4.8 \pm 2.3^{\mathrm{B}, \mathrm{b}}$ & $6.3 \pm 2.0^{\mathrm{A}, \mathrm{a}}$ & $4.2 \pm 0.7^{\mathrm{B}, \mathrm{b}}$ & $5.1 \pm 0.6^{\mathrm{A}, \mathrm{b}}$ \\
\hline AD35 & $58.6 \pm 2.3^{\mathrm{A}, \mathrm{b}}$ & $53.5 \pm 4.5^{\mathrm{A}, \mathrm{b}}$ & $6.7 \pm 2.2^{\mathrm{A}, \mathrm{a}}$ & $3.5 \pm 1.3^{\mathrm{B}, \mathrm{b}}$ & $6.0 \pm 1.1^{\mathrm{A}, \mathrm{a}}$ & $5.9 \pm 1.0^{\mathrm{A}, \mathrm{a}}$ \\
\hline
\end{tabular}

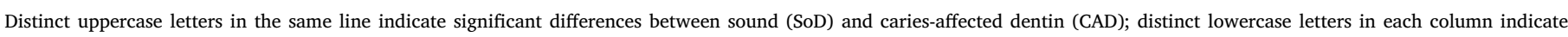
significant differences between the adhesives containing $5 \mathrm{wt} \%$ (AD5), $20 \mathrm{wt} \%$ (AD20), or $35 \mathrm{wt} \%$ (AD35) acidic monomer (p < 0.05).

* Statistical comparisons are restricted to each storage time. 
$24 \mathrm{~h}$

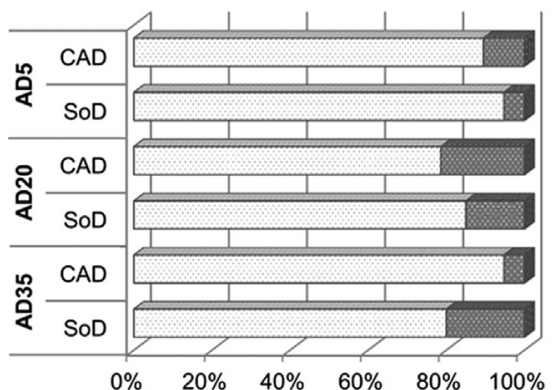

6 months

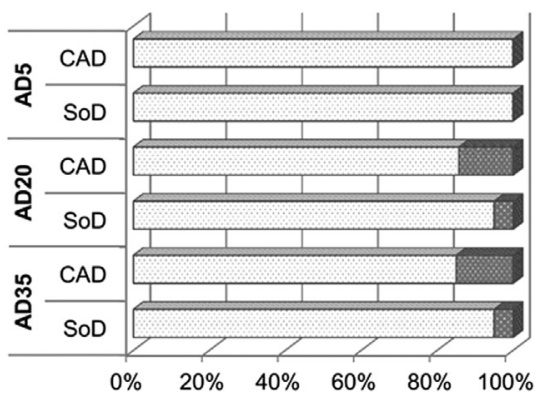

Fig. 2. Distribution of the failure modes in immediate and 6 months groups. Adhesive: failure between composite and dentin; Mixed: failure partially adhesive and partially cohesive within the dentin.

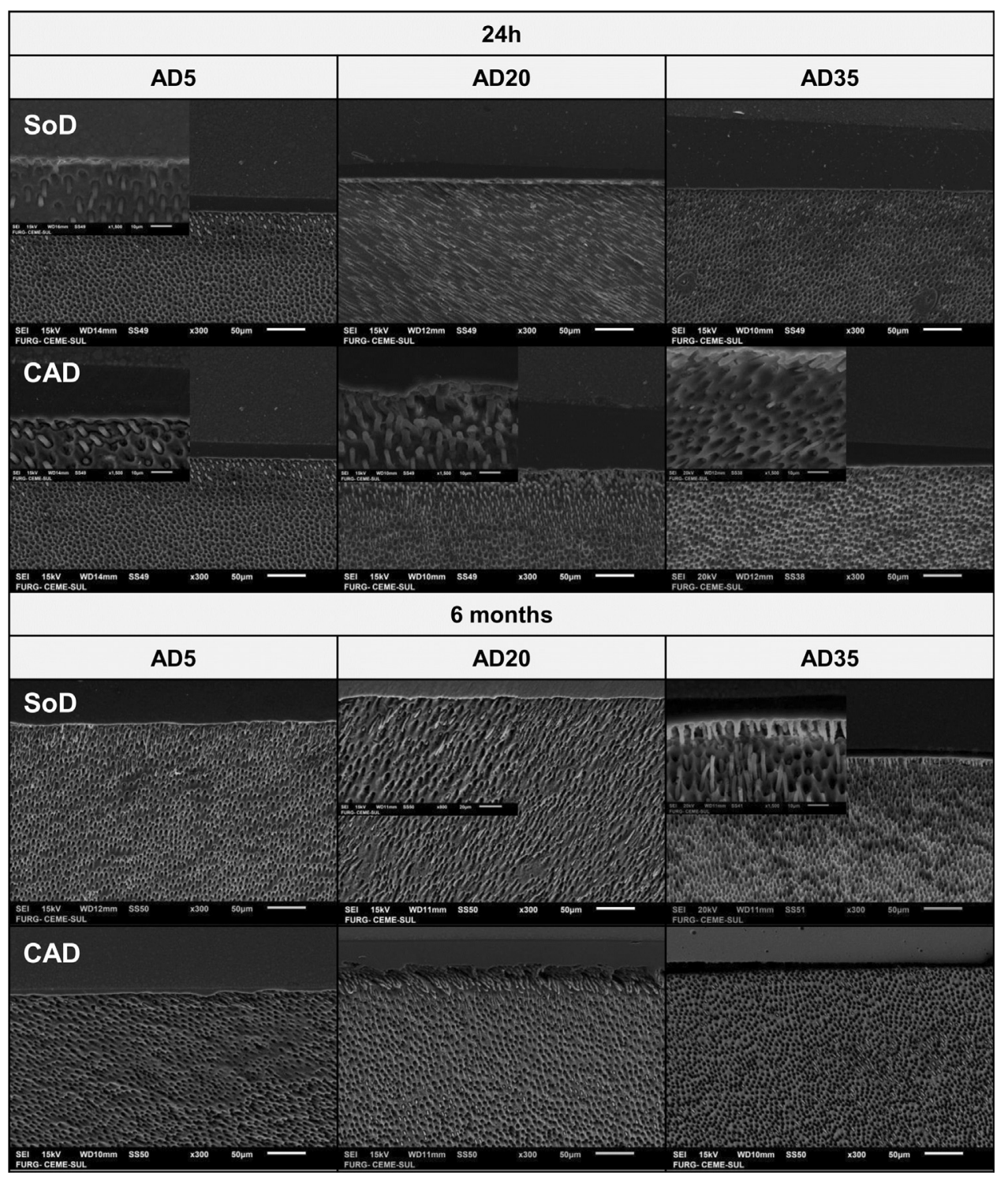

Fig. 3. SEM micrographs of the bonded interfaces formed between the experimental adhesives and SoD or CAD (magnifications: $\times 300$ and $\times 1500$ for the insert images). Both dentin substrates were impregnated by the adhesives in a similar mode. The SoD surface was always flat, whereas the CAD surface was irregular in some cases. The hybrid layer was generally thicker in CAD than in SoD.

the viscosity of the comonomer was increased. However, the presence of water and ethanol as solvents reduced the viscosity of all adhesives significantly. In general, higher contents of acidic monomers generally improved the dentin bond strengths, with results dependent on both the substrate type and water storage period. However, taking into account the results for the in situ DC, $35 \mathrm{wt} \%$ may be considered an excessive concentration of acidic monomer in self-etch adhesives.

It is well accepted that acidic methacrylates may not interact with hard dental tissues through an exclusive acid-dependent mechanism, but also through a process known as adhesion-decalcification $[38,39]$. This concept states that an acidic molecule is able to chemically interact with hydroxyapatite forming a calcium salt; depending on the stability of the salt, the acid may remain bonded to (adhesion) or debond from (decalcification) the substrate [32]. To fully understand the effect of this concept on the present findings, two points should be considered. The first one is that SoD is morphologically different from CAD, the former having a mineralized substrate with tubules occluded only by smear layer, whereas the latter has a partially demineralized 
Table 3

Medians (minima-maxima) for total count of the exposed collagen found for each group tested.

\begin{tabular}{|c|c|c|c|c|c|c|}
\hline \multirow[t]{2}{*}{ Adhesive } & \multicolumn{2}{|l|}{$24 \mathrm{~h}$} & \multicolumn{2}{|l|}{6 months } & \multicolumn{2}{|c|}{ Average fold increase* } \\
\hline & SoD & $\mathrm{CAD}$ & SoD & $\mathrm{CAD}$ & SoD & $\mathrm{CAD}$ \\
\hline AD55 & $3(0-20)^{\mathrm{A}, \mathrm{ab}}$ & $0(0-116)^{\mathrm{A}, \mathrm{a}}$ & $76(0-147)^{\mathrm{A}, \mathrm{a}}$ & $94(37-176)^{\mathrm{A}, \mathrm{a}}$ & 9.5 & 4.3 \\
\hline AD20 & $0(0-2)^{\mathrm{B}, \mathrm{b}}$ & $33(4-93)^{\mathrm{A}, \mathrm{a}}$ & $5(0-36)^{\mathrm{A}, \mathrm{b}}$ & $5(3-139)^{\mathrm{A}, \mathrm{a}}$ & 28.8 & 1.2 \\
\hline AD35 & $69(12-125)^{A, a}$ & $7(0-69)^{\mathrm{A}, \mathrm{a}}$ & $46(3-274)^{\mathrm{A}, \mathrm{a}}$ & $18(0-108)^{\mathrm{A}, \mathrm{a}}$ & 1.1 & 1.4 \\
\hline
\end{tabular}

SoD: sound dentin; CAD: caries-affected dentin. *24h vs. 6 months; values calculated based on average values.

For each storage time, distinct uppercase letters in the same line indicate significant differences between sound SoD and CAD; distinct lowercase letters in each column indicate significant differences between the adhesives containing $5 \mathrm{wt} \%$ (AD5), $20 \mathrm{wt} \%$ (AD20), or 35 wt $\%$ (AD35) acidic monomer $(\mathrm{p}<0.05)$.

intertubular dentin with mineral deposits potentially occluding the tubules $[20,28]$. Second, the three adhesives prepared in this study have different acidic potentials: AD5, AD20, and AD35 can be accordingly classified as 'mild' ( $\mathrm{pH}$ around 2), 'intermediately strong' ( $\mathrm{pH}$ between 1 and 2), and 'strong' $(\mathrm{pH} \leq 1)$ self-etch adhesives [32]. At $24 \mathrm{~h}$, while the bonding performance to SoD was better for AD35, this adhesive had the poorest bonding ability to CAD. In contrast, AD20 performed better in CAD than in SoD. AD35 was likely too acidic for application in the already demineralized CAD, over-etching the substrate. By contrast, the use of the moderately strong AD20 allowed a proper balance between demineralization and resin infiltration of the substrate. In corroboration, more than $20 \%$ of mixed failures were observed in SoD treated with AD35 and in CAD treated with AD20. The SEM micrographs also showed an over-demineralized aspect of CAD treated with AD35.

One of the major disadvantages of one-step adhesives is their excessive hydrophilicity derived from the presence of acidic species and water. This makes the adhesives more prone to attract water molecules from the dentin, for instance [27]. As the adhesive layer acts as a semipermeable membrane even after polymerization, water may diffuse through the hybrid layer and reach the bonded interface [29]. Such permeability contributes to polymer hydrolysis and degradation of the resin-dentin interface over time $[7,8]$. In contrast to previous studies $[1,6,33]$, the present findings demonstrated generally a stable adhesion upon storage, except in two groups: SoD treated with AD5 (decreased bond strengths at 6 months), and CAD treated with AD35 (improved bond strengths after 6 months). The composition of the adhesives differed only in the content of GDMA-P and HEMA as a consequence. A previous study showed that incorporation of more than $10 \mathrm{wt} \%$ of HEMA into self-etch adhesives had no advantageous effects on the adhesive performance [31]. Therefore, considering that the adhesives AD5, AD20, and AD35 were constituted by 40,25 , and $10 \mathrm{wt} \%$ of HEMA, faster hydrolytic degradation processes could be expected for substrates treated with AD5. In this scenario, the dentin bonding is challenged by hydrolytic activity and the adhesive may debond from the substrate (decalcification). The bonding performance of AD5 applied to SoD, comparing $24 \mathrm{~h}$ and 6 months results, corroborates this assumption. However, this holds true only for SoD; a more in-depth explanation should rely on other phenomena, including the total amount of exposed collagen at the bonded interface. After 6 months, the amount of exposed collagen for groups treated with AD5 was 9.5 times higher in SoD and only 4.3 times higher in CAD, indicating that more hydrolysis occurred in SoD than in CAD samples. It seems that the presence of demineralized dentin facilitated resin infiltration and interlocking with the exposed collagen fibrils, reducing the degradation and consequently the exposure of new collagen fibrils over time.

Histological staining differences between CAD and SoD are usually dependent on the availability of exposed collagen for reaction with the Goldner's Masson trichrome stains. The presence of partially demineralized dentin in CAD indicates more exposure of collagen fibrils. By contrast, the underlying intact dentin is packed by minerals. In CAD, even the collagen partially or fully degraded by the cariogenic process is stained. Although the bond strength to CAD treated with AD35 was low at $24 \mathrm{~h}$, it was higher compared to the other adhesives after 6 months of water storage. The amount of exposed collagen in CAD at $24 \mathrm{~h}$ was low when AD35 was applied, thus it can be expected that most collagen fibrils were impregnated by the adhesive. As a consequence, less degradation occurred upon storage. In addition, the greater variability and more irregular topography of CAD [20] compared with SoD may have contributed to improving the micromechanical interlocking of the adhesive. Therefore, the hypothesis tested was rejected.

\section{Conclusions}

The experimental one-step adhesives containing different concentrations of acidic monomer had similar bonding performances to SoD and CAD. The bonding effectiveness was dependent on factors such as the concentration of acidic monomer, acidity of the adhesive, and water storage period. The adhesive with $20 \%$ acidic monomer showed the highest in situ $\mathrm{C}=\mathrm{C}$ conversion and yielded stable dentin bond strengths that were generally independent of the dentin substrate tested.

\section{Acknowledgments}

The present study was carried out with support from the Coordination for the Improvement of Higher Education Personnel CAPES/PROCAD, Brazil. We thank Esstech Inc. for donation of reagents used in the study and CEME-Sul - Centro de Microscopia Eletrônica da Zona Sul at Federal University of Rio Grande, Brazil for support with the SEM equipment.

\section{References}

[1] Abdalla AI. Effect of long-term water aging on microtensile bond strength of selfetch adhesives to dentin. Am J Dent 2010;23:29-33.

[2] Arrais CAG, Giannini M, Nakajima M, Tagami J. Effects of additional and extended acid etching on bonding to caries-affected dentine. Eur J Oral Sci 2004;112:458-64.

[3] Daculsi G, LeGeros RZ, Jean A, Kerebel B. Possible physico-chemical processes in human dentin caries. J Dent Res 1987;66:1356-9.

[4] De Munck J, Vargas M, Iracki J, Van Landuyt K, Poitevin A, Lambrechts P, et al. One-day bonding effectiveness of new self-etch adhesives to bur-cut enamel and dentin. Oper Dent 2005;30:39-49.

[5] Dieng-Sarr F, Sharrock P, Dabsie F, Grégoire G. Modifications of the organic and mineral fractions of dental tissues following conditioning by self-etching adhesives. J Dent 2011;39:141-7.

[6] Erhardt MC, Toledano M, Osorio R, Pimenta LA. Histomorphologic characterization and bond strength evaluation of caries-affected dentin/resin interfaces: effects of long-term water exposure. Dent Mater 2008;24:786-98.

[7] Hashimoto M, Ohno H, Sano H, Kaga M, Oguchi H. In vitro degradation of resindentin bonds analyzed by microtensile bond test, scanning and transmission electron microscopy. Biomaterials 2003;24:3795-803.

[8] Hashimoto M, Tay FR, Ohno H, Sano H, Kaga M, Yiu C, et al. SEM and TEM analysis of water degradation of human dentinal collagen. J Biomed Mater Res B Appl Biomater 2003;66:287-98.

[9] Joves GJ, Inoue G, Nakashima S, Sadr A, Nikaido T, Tagami J. Mineral density, morphology and bond strength of natural versus artificial caries-affected dentin. 
Dent Mater J 2013;32:138-43.

[10] Kaaden C, Powers JM, Friedl KH, Schmalz G. Bond strength of self-etching adhesives to dental hard tissues. Clin Oral Investig 2002;6:155-60.

[11] Leal FB, Madruga FC, Prochnow EP, Lima GS, Ogliari FA, Piva E, et al. Effect of acidic monomer concentration on the dentin bond stability of self-etch adhesives Int J Adhes Adhes 2011;31:571-4.

[12] Madruga FC, Ogliari FA, Ramos TS, Bueno M, Moraes RR. Calcium hydroxide, pHneutralization and formulation of model self-adhesive resin cements. Dent Mater 2013;29:413-8.

[13] Maltz M, Alves LS, Jardim JJ, Moura MS, de Oliveira EF. Incomplete caries removal in deep lesions: a 10-year prospective study. Am J Dent 2011;24:211-4.

[14] Marshall GW, Habelitz S, Gallagher R, Balooch M, Balooch G, Marshall SJ. Nanomechanical properties of hydrated carious human dentin. J Dent Res 2001;80:1768-71.

[15] Maske TT, Isolan CP, van de Sande FH, Peixoto AC, Faria ESAL, Cenci MS, et al. A biofilm cariogenic challenge model for dentin demineralization and dentin bonding analysis. Clin Oral Investig 2015;19:1047-53.

[16] Moraes RR, Faria-e-Silva AL, Ogliari FA, Correr-Sobrinho L, Demarco FF, Piva E. Impact of immediate and delayed light activation on self-polymerization of dualcured dental resin luting agents. Acta Biomater 2009;5:2095-100.

[17] Moraes RR, Guimarães GZ, Oliveira AS, Faot F, Cava SS. Impact of acidic monomer type and concentration on the adhesive performance of dental zirconia primers. Int J Adhes Adhes 2012;39:49-53.

[18] Munchow EA, da Silva AF, da Silveira Lima G, Wulff T, Barbosa M, Ogliari FA, et al. Polypropylene glycol phosphate methacrylate as an alternative acid-functional monomer on self-etching adhesives. J Dent 2015;43:94-102.

[19] Nakajima M, Kunawarote S, Prasansuttiporn T, Tagami J. Bonding to caries-affected dentin. Jpn Dent Sci Rev 2011;47:102-14.

[20] Nakajima M, Sano H, Zheng L, Tagami J, Pashley DH. Effect of moist vs. dry bonding to normal vs. caries-affected dentin with Scotchbond Multi-Purpose Plus. J Dent Res 1999;78:1298-303.

[21] Navarra CO, Cadenaro M, Armstrong SR, Jessop J, Antoniolli F, Sergo V, et al. Degree of conversion of Filtek Silorane Adhesive System and Clearfil SE Bond within the hybrid and adhesive layer: an in situ Raman analysis. Dent Mater 2009;25:1178-85.

[22] Ogawa K, Yamashita Y, Ichijo T, Fusayama T. The ultrastructure and hardness of the transparent layer of human carious dentin. J Dent Res 1983;62:7-10.

[23] Oliveira AS, Kaizer MR, Azevedo MS, Ogliari FA, Cenci MS, Moraes RR. (Super) hydrophobic coating of orthodontic dental devices and reduction of early oral biofilm retention. Biomed Mater 2015;10:065004.

[24] Pashley DH, Tay FR, Breschi L, Tjaderhane L, Carvalho RM, Carrilho M, et al. State of the art etch-and-rinse adhesives. Dent Mater 2011;27:1-16.

[25] Selwitz RH, Ismail AI, Pitts NB. Dental caries. Lancet 2007;369:51-9.

[26] Spencer P, Swafford JR. Unprotected protein at the dentin-adhesive interface.
Quintessence Int 1999;30:501-7.

[27] Tay FR, Pashley DH. Have dentin adhesives become too hydrophilic? J Can Dent Assoc 2003;69:726-31.

[28] Tay FR, Pashley DH, Hiraishi N, Imazato S, Rueggeberg FA, Salz U, et al. Tubular occlusion prevents water-treeing and through-and-through fluid movement in a single-bottle, one-step self-etch adhesive model. J Dent Res 2005;84:891-6.

[29] Tay FR, Pashley DH, Suh BI, Carvalho RM, Itthagarun A. Single-step adhesives are permeable membranes. J Dent 2002;30:371-82.

[30] van de Sande FH, Azevedo MS, Lund RG, Huysmans MC, Cenci MS. An in vitro biofilm model for enamel demineralization and antimicrobial dose-response studies. Biofouling 2011;27:1057-63.

[31] Van Landuyt KL, Snauwaert J, Peumans M, De Munck J, Lambrechts P, Van Meerbeek B. The role of HEMA in one-step self-etch adhesives. Dent Mater 2008;24:1412-9.

[32] Van Meerbeek B, Yoshihara K, Yoshida Y, Mine A, De Munck J, Van Landuyt KL. State of the art of self-etch adhesives. Dent Mater 2011;27:17-28.

[33] Vanajasan PP, Dhakshinamoorthy M, Rao CS. Factors affecting the bond strength of self-etch adhesives: a meta-analysis of literature. J Conserv Dent 2011;14:62-7.

[34] Vasconcelos AC, Berti-Couto SA, Azambuja AA, Salum FG, Figueiredo MA, da Silva VD, et al. Comparison of effects of clodronate and zoledronic acid on the repair of maxilla surgical wounds - histomorphometric, receptor activator of nuclear factor$\mathrm{kB}$ ligand, osteoprotegerin, von Willebrand factor, and caspase- 3 evaluation. J Oral Pathol Med 2012;41:702-12.

[35] Wong L, Sissons C. A comparison of human dental plaque microcosm biofilms grown in an undefined medium and a chemically defined artificial saliva. Arch Oral Biol 2001;46:477-86.

[36] Wong L, Sissons CH. Human dental plaque microcosm biofilms: effect of nutrient variation on calcium phosphate deposition and growth. Arch Oral Biol 2007;52:280-9.

[37] Xuan W, Hou BX, Lu YL. Bond strength of different adhesives to normal and cariesaffected dentins. Chin Med J 2010;123:332-6.

[38] Yoshida Y, Van Meerbeek B, Nakayama Y, Yoshioka M, Snauwaert J, Abe Y, et al. Adhesion to and decalcification of hydroxyapatite by carboxylic acids. J Dent Res 2001;80:1565-9.

[39] Yoshioka M, Yoshida Y, Inoue S, Lambrechts P, Vanherle G, Nomura Y, et al. Adhesion/decalcification mechanisms of acid interactions with human hard tissues. J Biomed Mater Res 2002;59:56-62.

[40] Zanchi CH, D'Avila OP, Rodrigues SA, Burnett LH, Demarco FF, Pinto MB. Effect of additional acid etching on bond strength and structural reliability of adhesive systems applied to caries-affected dentin. J Adhes Dent 2010;12:109-15.

[41] Zhang Y, Wang Y. The effect of hydroxyapatite presence on the degree of conversion and polymerization rate in a model self-etching adhesive. Dent Mater 2012;28:237-44. 